\title{
USING ROLE-PLAY TO SUPPORT COMMUNICATION INSTRUCTION FOR ENGINEERS
}

\author{
Theresa Merrick and Lydia Wilkinson \\ Engineering Communication Program, University of Toronto \\ theresa.merrick@utoronto.ca, lydia.wilkinson@utoronto.ca
}

\begin{abstract}
By adapting the learning models of $e$ based role-play University of Toronto communication instructors use a mock interview to create a more acceptable gateway into engineering expertise.
\end{abstract}

\section{INTRODUCTION}

Communication instructors within engineering faculties often have a background that qualifies them for writing instruction while lacking technical expertise. This lack of shared disciplinary knowledge can cause students to question the credibility of their instructors.

Their skepticism can be at least temporarily alleviated through role-play-simulations that replicate the real work environment. This kind of learning model builds on the theoretical work of Herrington, Reeves \& Oliver (2010) and Wills, Leigh \& Ip (2011), who demonstrate that role-play provides moments of high-quality learning. In particular, nine "elements of authentic learning" are emphasized. Here, we focus on four of them: "[providing] authentic contexts that reflect the way the knowledge will be used in real life; [providing] access to expert performances and the modelling of processes; [providing] multiple roles and perspectives; [supporting] collaborative construction of knowledge" [1].

\section{ROLE-PLAY IN THE PORTFOLIO}

The second year Chemical Engineering portfolio at the University of Toronto provides a useful example of the way in which role-play can create an entry point for positive student-instructor collaboration. In this course students are asked to assemble samples of exemplary work to produce a professional portfolio. Each student is assigned a communication instructor (CI) who is available throughout the year as they gather or produce these items. In this way the CI is first introduced as a general resource for all communication, which students can choose to use based on their individual needs. In early January students participate in their first mandatory activity with their CI, a mock interview, which provides instructors with a space to critique the student's resume while giving students an opportunity to practice their interview skills. These interviews are not heavily scripted; instead, instructors are expected to adapt these to the individual interests of their students based on specific requests and the content of their resumes. The interview is followed by an informal feedback session.

\section{DISCUSSION}

These interviews shift the communication instructor's role from general support to professional expert within a simulated professional environment. For the communication instructor this shift is fluid: throughout the year they have been acting as expert audience for the portfolio, helping students to understand what types of work can best showcase their strengths to a professional audience. Their physical embodiment of this expert role however, marks a more concrete transition from CI to professional expert. Switching between these two identities during the interview and feedback session underscores their advantageous position as approachable resource and professional expert.

This exercise incorporates the elements of authentic learning by: creating a real life context in the interview; relying on the expert performance of the CI, who models the interview process; providing access to the multiple perspectives of the interviewer/instructor; and facilitating the collaborative construction of knowledge as the student and CI define the parameters of this interview in advance. This instructional paradigm allows instructors to achieve greater success by harnessing student interest, which allows them to share their actual expert knowledge as critical thinkers, communicators and rhetoricians on other core assignments across the curriculum.

\section{WORKS CITED}

[1] Jan Herrington, Thomas C. Reeves, and Ron Oliver, $A$ Guide to Authentic e-Learning. New York: Routledge, 2010, 216 pp. \{ISBN: 978-0415998000\}

[2] Sandra Wills, Elyssebeth Leigh, and Albert Ip, The Power of Role-based e-Learning: Designing and Moderating Online Role Play. New York: Routledge, 2010, 280 pp. \{ISBN: 978-0415877855\} 